\title{
Thermodynamic and Structural Studies on the Human Serum Albumin in the Presence of a Polyoxometalate
}

\author{
D. Ajloo, ${ }^{*}$ H. Behnam, A. A. Saboury ${ }^{\dagger}$ F. Mohamadi-Zonoz, B. Ranjbar, \\ A. A. Moosavi-Movahedi, ${ }^{\dagger}$ Z. Hasani, ${ }^{\ddagger}$ K. Alizadeh, ${ }^{\S}$ M. Gharanfoli, ${ }^{\dagger}$ and M. Amani ${ }^{\ddagger}$ \\ Facthy of Chemistry, Damghan Lniversity of Basic Science, Damghan, Iran. "E-mail ajlooaldubs ac.ir \\ Institute of Biochemistry and Biophysics, The University of Tehran, Tehran, Iran \\ -Department of Biophysics, Faculty of Basic Science, Tarbiat Hodarres Lniversity, Tehran, Iran \\ "Deparment of Chemistry, Factht of Basic Science, Tarbiat Hodarres Lniversity, Tehran, Iran \\ Received December 28, 2006
}

\begin{abstract}
The interaction of a polyoxometal (POM). $\mathrm{K}_{6} \mathrm{SiW}_{11} \mathrm{Co}\left(\mathrm{H}_{2} \mathrm{O}\right) \mathrm{O}_{39} .10 \mathrm{H}_{2} \mathrm{O}\left(\mathrm{K}_{6}\right)$ as a Keggin. with human senum albumin (HSA) was stidied by different methods and techniques. Binding studies show two sets of binding sites for interaction of POM to HSA. Binding analysis and isothermal calorimetery revealed that the first set of binding site has lower number of bound ligand per mole of protein ( $v$ ). lower Hill constant (n). higher binding constant $(K)$. more negative entropy ( $\Delta S$ ) and more electrostatic interaction in comparison to the second set of binding site. In addition. differential scanning calorimetery (DSC) and spectrophotometery data showed that there are two energetic domains. The first domain is less stable (lower $T_{m}$ and $C_{p}$ ) which corresponds to the tail segment of HSA and another with more stability is related to the head segment of HSA. Polyoxometal also decreases the stability of protein as $T_{m}$. secondary and tertiary stnucture as well as quenching of the fluorescence decrease. On other hand. perturbations in tertiary structure are more than secondary structure.
\end{abstract}

Key Words : Polyoxometalate. Human serum albumin. Isothermal titration calorimetery, Circular dichroism, Fluorescence

\section{Introduction}

Albumin is a major plasma protein and binds to the number of drugs altering their pharmacokinetics. It is single chain polypeptide of 585 residues. which comprises about $60 \%$ of the plasma protein. It is the major contributor to the oncotic of blood. ' In addition. it has been reported that albumin is chiefly responsible for maintainance of blood $\mathrm{pH}^{23}$ The human serum albumin (HSA) is named a multifunctional plasma carrier protein because of its ability to bind to an unusually broad spectrum of ligands. These includes inorganic cations. organic anions various dnugs. amino acids. and perhaps most important and physiologically available hydrophobic molecules such as bilirubin and fatty acids. ${ }^{1.4 .5}$

In mammals. albumin is sy'nthesized by the liver and possesses a half-life in circulation of 19 days ${ }^{6.7}$ Serum albumin has been one of the most studied proteins for 40 years. because its primary structure is very well known for a long time and its tertiary structure was determined a few years ago by $\mathrm{X}$-ray crystallography ${ }^{56}$ Its primary structure is characterized by low content of tryptophan. a high content of cystein stabilizing a series of main loops. and charged amino acids such as aspartic and glutamic acids. lysine and arginine. ${ }^{5}$ The apparent repeating stnuctural features. large and small loops and connecting segments. suggest that albumin evolved through a series of gene duplications. Its secondary structure is constituted of $67 \%$ of helix of six turns and 17 disulfide bridge. ${ }^{5.8}$ The tertiary structure is composed by three domains I. II. III. Each domain is constituted by a cylinder formed by six helices. and each one of these domains are constituted by two subdomains formed by three helices that covalently linked by their double Cys bridge. These subdomains are IAB. IC. IIAB. IIC. IIIAB. IIIC 50 The binding cavity in the domain IIIA is known to be able to bind many ligands like, for example. digitoxin. ibuprofen and tryptophan. Aspirin and iodinated aspirin derivatives show nearly equal distributions between the binding sites located in subdomains IIA and IIIA. Warfarin occupies a single site in IIA ti. Many small aromatic carboxylic acids are equally distributed in both IIA and IIIA ${ }^{\text {Since domains }}$ II and III share a common interface. It is known that binding to domain III leads to conformational changes affecting the binding affinities to domain II. Trp214 residue plays an important structural role in the formation of the IIA binding site by limiting the solvent accessibility and besides that it participates in additional hydrophobic packing interactions at IIA-IIIA interface. ${ }^{7} \mathrm{Cy}$ ' 34 used as a fluorescent probe to monitor the surroundings of this residue . $10.12^{-12}$

On the other hand. same as all of ligands. several compounds such as polysulfates. polysulfunates. polycarboxylates. polyphosphates and polyoxometalates (POM) have been identified that pharmaceutical effect and inhibit an early stage in the replicative cycle of the human immunodeficiency virus (HIV). ${ }^{1 \mathfrak{3}}$ Polyoxometalates are early transition metal oxygen anion clusters. More specifically. they are oligomeric aggregates of metal cations (usually the $d^{\circ}$ species $\mathrm{V}^{\mathrm{V}} \cdot \mathrm{Nb}^{\mathrm{V}}, \mathrm{Ta}^{\mathrm{V}} \cdot \mathrm{Mo}^{\mathrm{V}}$. and $\mathrm{W}^{\mathrm{V}}$ bridged by oxide anions that are formed by self-assembly processes. There are two generic families of POMs. the isopoly and the heteropoly 
compounds. Several general attributes of POMs render them attractive for applications in medicine. The principle advantageous feature of POMs is that nearly every molecular property that impacts the recognition and reactivity of POMs with target biological molecules can be altered. These include polarity. redox potentials, surface charge distribution. shape. and acidity. ${ }^{14}$

Polyoxometalates have various molecular and electronic structures with analytical. biological. clinical. geochemical and topological applications. ${ }^{15}$ In particular. these compounds have attracted attention in view of their potential application in catalysis ${ }^{15,16}$ and as antiviral and antitumoral agents. These complexes exhibited biological activity as new potent class of anti-HIV drugs. Interaction of these drugs and their derivatives with biological structures is one of considerable interest. since they have possible medical applications. ${ }^{1+15}$ Two general types of POM activity, antiviral and antitumoral, have dominated the medicinal chemistry of these compounds to date. The polyoxometalates block the binding of HIV particles to the CD4 cells. ${ }^{15}$ They block the binding of recombinant gpl20 to SUP-Tl cells in a concentrationdependent manner. They also inhibited the binding of antigpl20 mAb to HIV-1-infected MT-4 cells. The principal disadvantage of POMs is that they are not organic species. Because low molecular weight organic species dominate in the phannacentical industry (drug discovery. synthesis. and development). Increasing the charge and formula weight make enhance the $\mathrm{IC}_{50}$ and $\mathrm{EC}_{50 .}{ }^{1+}$

Thus, the interaction of POM (as a drug) and HSA (as a carrier) is significant and is also of interest. Interaction of potassium dodecatangestato cobaltate (III) (PDC) with bovine serum albumin using fluorescence spectroscopy was studied by Bordbar et al.. ${ }^{18}$ They investigated the binding of PDC as a water-soluble polyoxometal with bovine serum albumin (BSA) by fluorescence. It has been concluded that binding of this POM to BSA quenches protein emission. The interpretation of the results represents that binding affinity depends on both electrostatic forces and conformational stability of BSA. A step-by-step aggregation model. which was show that the binding of PDC to BSA dose not induces any considerable aggregation in BSA molecules. Therefore. they concluded that there are no conformational changes in BSA molecules during its interaction with $\mathrm{PDC}$.

Binding of ligands to macromolecules were previously studied by different methods such as: equilibrium dialy'sis ${ }^{153}$ dynamic dialysis ${ }^{21.23}$ electrochenical ${ }^{23,24}$ calorimetery ${ }^{25}$ spectrophotometery. ${ }^{26}$ In this study we have investigated the interaction of a polyoxometal with human serum albumin by different methods and techniques. The aim of this work is the investigation of effect of POM on the structure of human senum albumin

\section{Materials and Methods}

Materials. $\mathrm{K}_{6} \mathrm{SiW}_{11} \mathrm{Co}\left(\mathrm{H}_{2} \mathrm{O}\right) \mathrm{O}_{3 ! 1} 10 \mathrm{H}_{3} \mathrm{O}\left(\mathrm{K}_{6}\right)$ with $\mathrm{FW}=$ 3166. $\varepsilon$ (at $250 \mathrm{~nm}$ ) $=36300 \mathrm{M}^{-1} \mathrm{~cm}^{-1}$. was prepared and purified by literatures methods. ${ }^{27.99}$ Human serum albunin.
HSA, (free fatty acid) was obtained from Flucka Chemical $\mathrm{Co}$.. and used as received. All of the other chemicals were in analytical grades and purchased from Merck and Sigma chemical $\mathrm{Co}$. The POM and HSA solutions were freshly prepared in all experiments. before spectral analysis. The solutions were prepared with double distilled deionized water. Dialysis bag ultra pure, life technology. $3 / 4$ inch diameter, 14000 Daltons cut-off was purchased from GIBCOBRL Co.

\section{Methods}

Isothermal titration microcalorimetery: Enthalpy measurements were carried out with a four-channel commercial microcalorimetery (Thermal activity monitor 2277, Thermometric, Sweden). Every time. $20 \mu \mathrm{L}$ of $0.5 \mathrm{mM}$ ligand $\left(\mathrm{K}_{6}\right)$ solution was injected into the calorimetric vessel which contained $2 \mathrm{~mL}$ of HSA ( $1 \mathrm{mg} / \mathrm{mL})$ in $10 \mathrm{mM}$ phosphate buffer $(\mathrm{pH} 6)$ by using a Hamilton syringe. The injection of ligand into the perfusion vessel was repeated 20 times. The enthalpy change for each injection was calculated by "Digitam 3" computer program. The enthalpy of dilution of the ligand solutions were measured as described above when the HSA protein was excluded. The enthalpy of dilution for the ligand was subtracted from the enthalpy of proteinligand interaction. The enthalpy of dilution of HSA is negligible. The molar mass of the HSA protein was taken 66500 Dalton for all calculation.

UV-Vis spectrophotometery: The effect of POM on thermal stability of POM was also investigated by thermal scanning UV-Vis spectrophotometer. Carry 100-Bio model. Variation of absorbance at $280 \mathrm{~nm}\left(\% \Delta \mathrm{A}_{28}\right)$ versus temperature $\left(30-90^{\circ} \mathrm{C}\right)$ with $\mathrm{I} \mathrm{K} / \mathrm{min}$ scan rate was studied at $\mathrm{pH}=$ 6 and $10 \mathrm{mM}$ phosphate buffer. Initial volume of buffer was $600 \mu \mathrm{L}$. This experiment carried out in the first for $0.5 \mathrm{mg} /$ $\mathrm{mL}$ of HSA in the absence of POM then studied in the presence of $3 \times 10^{-5} \mathrm{M}$ POM in the same condition. Inflection point of above curve $\% \Delta A_{2 s(1)}$ is $T_{n}$ or melting point that is a criterion for stability of protein.

Circular dichroism spectroscopy measurements: Circular dichroism measurements were performed with a Jasco J-715 spectropolarimeter. The samples were analyzed in quartz cells with path lengths of $1 \mathrm{~mm}$. Far-UV and near-UV wavelength scans were recorded from 200 to $250 \mathrm{~nm}$ and 250 to $320 \mathrm{~nm}$. respectively: All the CD spectra were corrected by subtraction of the background for the spectrum obtained with either buffer alone or buffer containing the ligand. The observed ellipticity in degree $\left(\theta_{c t s}\right)$ results were expressed as mean residue ellipticity. $\left[\theta_{i}\right.$, in degrees $\mathrm{cm}^{2}$ $\mathrm{dmol}^{-1}$. Secondary and tertiary structure of HSA in the absence and presence of 4.9 and 14 fold concentration of POM investigated in $10 \mathrm{mM}$ phosphate buffer $\mathrm{pH} 6$ and 27 ${ }^{\circ} \mathrm{C}$. Far-UV CD spectra region was used for the secondary structure and near UV-CD for tertiary structure. Concentration of HSA for secondary and tertiary structures were 0.3 $\mathrm{mg} / \mathrm{mL}$ and $3 \mathrm{mg} / \mathrm{mL}$ respectively. The molar ellipticity was calculated on the basis of the following equation:

$$
[\theta]_{i}=\frac{100 M R W \theta_{\lambda}}{C \times 1}
$$


Where C. / and MRW are protein concentration in $\mathrm{mg} / \mathrm{ml}$. the length of light path in $\mathrm{cm}$ and mean anino acid residue weight, respectively.

Steady-state fluorescence measurements: Steady-state fluorescence measurements were performed with a Luminescence Spectrometer LS 50B Perkin Elmer at $27^{\circ} \mathrm{C}$. A solution of $0.015 \mathrm{~mm} / \mathrm{mL}$ HSA was excited at $290 \mathrm{~nm}$ in the absence and presence of different volume of $5 \times 10^{-5} \mathrm{M}$ POM. The emission spectra were followed at $337 \mathrm{~nm}$. A 10 $\mathrm{mm}$ path length quartz cell with a Teflon stopper was used. Care was taken to avoid the presence of significant air pockets. The cuvette was placed in a thermostatically controlled cell holder with a temperature of accuracy $\pm 0.1^{\circ} \mathrm{C}$.

Differential scanning calorimetery: Differential scanning calorimetery of protein was studied by microcalorimeter Scal-I model with $2 \mathrm{~K} / \mathrm{min}$ scan rate. High pressure gas was used for prolibiting bubble formation. Thermogram for protein was corrected by subtracting from buffer. Volume of cell is approximately $300 \mu \mathrm{L}$, and protein and ligand concentration were $2.5 \times 10^{-5}$ and $4.5 \times 10^{-5} \mathrm{M}$, respectively.

Dynamic dialysis: In the first part of the experimental work. $2 \mathrm{~mL}$ of $10 \mathrm{mM}$ phosphate buffer solution, $\mathrm{pH}$ 6.0. containing of $2.5 \mathrm{mM}$ of $\mathrm{K}_{6}$ was put into a dialysis bag which was placed in $150 \mathrm{~mL}$ of buffer solution. in a way that the level of solution of inside and outside the bag became nearly identical. The outside solution was stirred regularly and POM concentration therein was measured every $10 \mathrm{~min}$. In the second part of the experiments, $2 \mathrm{~mL}$ of the buffer solution containing $2 \mathrm{mg} / \mathrm{mL}$ of protein was put into a bag. $\mathrm{K}_{6}$ concentration outside the dialysis tubing was measured as above.

For the standard curve. solutions of $\mathrm{K}_{6}$ with concentrations in the range of $0.2 \times 10^{-5} \mathrm{M}$ were prepared in the phosphate buffer and their absorption were determined at $250 \mathrm{~nm}$.

\section{Results and Discussion}

There are several methods for ligand binding investjgations. ${ }^{1: .26}$ Equilibriun dialysis is one of the most general methods for this purpose. A disadvantage of this method is being relatively time consuming and demanding for higher concentration of the sample in the experiment. On the other hand the dynamic dialy'sis method is relatively more precise. faster and requires less sample than equilibrium dialysis. The most important point is that. there is no absorbance interference in this method. Some of ligands and macromolecules may have absorbance interference in the studied wavelength. In this work. POM and HSA have a maximum absorbance at about $250 \mathrm{~nm}$ and $280 \mathrm{~nm}$ wavelengths. respectively. Thus to prohibit any absorbance interference in our studies. we have used the dynamic dialysis method. To obtain binding parameters. one need to evaluate the number of bound ligands to protein. Therefore, we present some of necessary equations for this purpose. ${ }^{21}$ The first Fick`s law states that:

$$
J=-D \frac{d C}{d x}
$$

Where. $J$ is flux, $D$ is the diffusion coefficient and $d C / d x$ is the gradient of concentration. Given in the experiments the volumes of the solutions inside and outside the bag are actually fixed, finite and stirred, thus:

$$
\frac{\Delta C}{\Delta x}=\frac{\left(C_{1}-C_{0}\right)}{d}
$$

and

$$
J_{i \rightarrow 0}=\frac{1}{A} \cdot \frac{d n}{d t}=-D \frac{C_{i}-C_{0}}{d}
$$

Where: $d$ is the constant thickness of the membrane, $n$ is the number of moles of ligand. $C_{2}$ and $C_{0}$ are the concentrations of ligand inside and outside, respectively, and $A$ is a constant.

Under the above conditions:

$$
\frac{d n}{d t} \propto \frac{d C_{i}}{d t} \propto-\frac{d C_{0}}{d t}
$$

and

$$
\frac{d C_{0}}{d t}=k\left(C_{3}-C_{0}\right)
$$

Where $k$ is a constant.

The equation (6) indicates that the variation of $d C d d t$ with $\Delta C=C_{i}-C_{0}$ should be linear. The values of $d C_{d} / d t$ can be determined at different times. $C_{2}$ can also be determined in the absence of the protein. thus $\Delta C=C_{2}-C_{0}$ is evaluated. The adsorption by membrane itself is neglected.

Although the equation (6) is not linear in practice, it can be used to construct a calibration curve. from which the

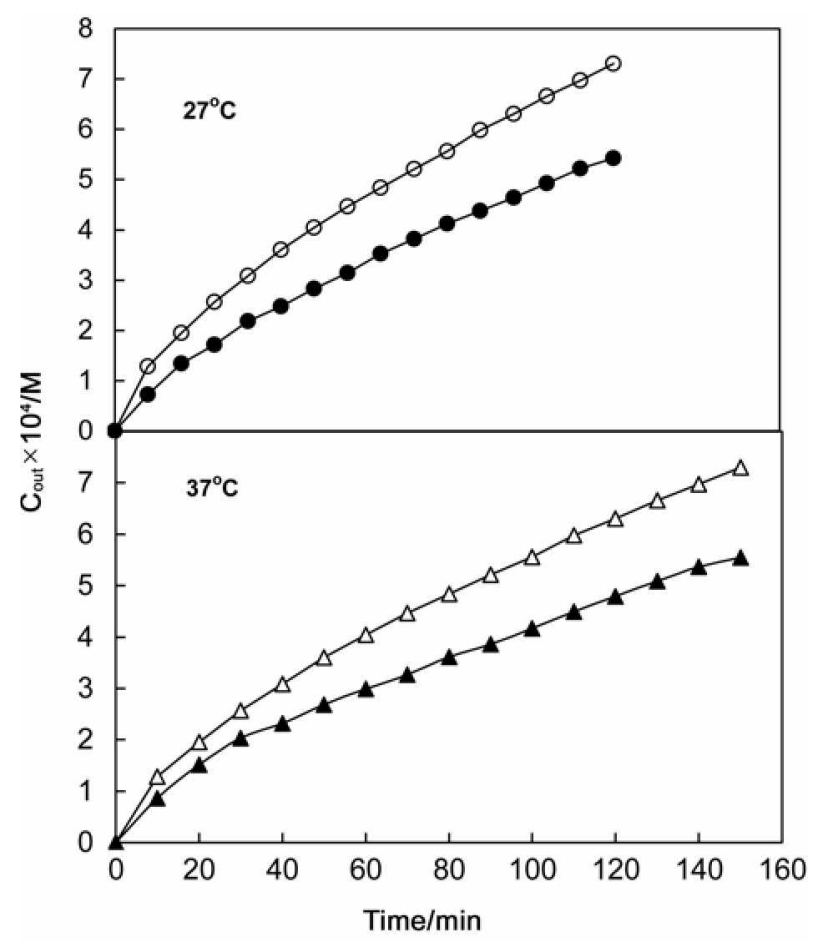

Figure 1. Variation of the concentration of POM outside the dialyze bag, in the absence (open) and presence (filled) of HSA against time. 

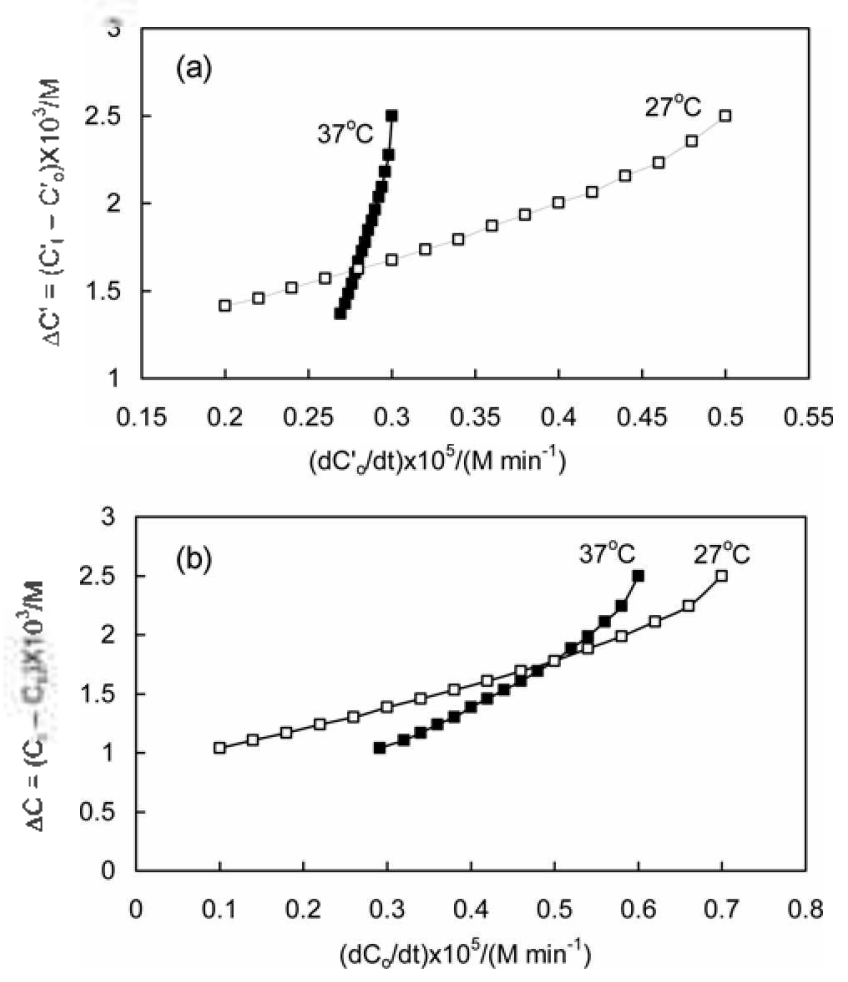

Figure 2. Calibration curve for estination of $\Delta C=C_{-j}^{+}-C_{0}$ at corresponding $d C_{0} / d t$ values in the presence (a) and absence (b) of HSA.

concentration of the free ligand in the presence of the protein $\left(C^{\prime} i\right)$ can be determined at a known ligand concentration outside the bag. $C_{0}^{\prime \prime}$. In the absence of the protein, the concentrations of the ligand diffused out, $C_{0}$. are measured at different times and the $C_{0}$ values plotted against $t$, (Fig. 1) wherefrom the rate $d C_{d} / d t$ values are obtained. By determining corresponding concentrations of the ligand inside the bag. the calibration curve, i.e. a plot of $d C_{0} / d t$ versts $\Delta C=$ $C_{i}-C_{0}$. is obtained (Fig. 2). In the presence of the protein the whole procedure is repeated and the rates. $d C_{0}^{\prime} / d t$ determined. Then for the same time intervals the corresponding values of $d C_{0}^{\prime} / d t$ and $C_{0}^{\prime}$ are selected and by the use of the calibration curve. (It is obvious that. when attaining equilibrium is faster than the rate of diffusion. the calibration curve could be used) the $\Delta C$ and $C_{i}$ values in the presence of the protein are obtained. For protein solution we write:

$$
\frac{d C_{0}^{\prime}}{d t}=k\left(C_{1}-C_{0}^{\prime}\right)
$$

The method was used to study the binding of $\mathrm{K}_{6}$ to HSA. Figure 1 shows the variation of $C_{0}$ against time in the absence and presence of HSA at 27 and $37^{\circ} \mathrm{C}$.

values of $d \mathrm{~K}_{0} / \mathrm{dt}$ corresponding to different values of $\mathrm{C}_{0}-$ $C_{i}$ at specified times were obtained and hence the calibration curve, that is $C_{i}-C_{0}$ verstis $d C_{d} / d t$, was obtained (cf. Fig. 2).

The value of $k$ depends on the size. surface of dialysis bag and diffusion of samples. In this experiment we compared the diffusion of POM in the absence and presence of HSA. Therefore. if all of the conditions become similar. the $k$ values are equal. Therefore by elimination of $k$ in two above equations. we obtain following equation:

$$
C_{i}^{\prime}=C_{0}^{\prime}+\left(C_{-}-C_{0}\right) \frac{d C_{0}^{\prime}}{d t} / \frac{d C_{0}}{d t}
$$

Then average number of ligand bound to the macromolecule. $v$. can be estimated using the following equation:

$$
v=\frac{C_{i}^{0}-C_{i}^{\prime}}{C_{p}}
$$

Where $C_{p}$ and $C_{i}^{\circ}$ are total concentration of the protein and initial concentration of the ligand, respectively. and $C_{i}^{\prime}$ was defined earlier and obtained by equation (8). Calorimetric and binding data has shown that we have two sets of binding sites. Thus, applying the Hill equation for two sets of binding sites ${ }^{79}$ we can obtain thenmodynamic parameters:

$$
v=\frac{g_{1}\left(K_{1} C_{i}^{\prime}\right)^{n_{1}}}{1+\left(K_{1} C_{i}^{\prime}\right)^{n_{1}}}+\frac{g_{2}\left(K_{3} C_{1}^{\prime}\right)^{n_{2}}}{1+\left(K_{2} C_{i}^{\prime}\right)^{n_{2}}}
$$

In this equation, $g_{l} . K_{1}$ and $n_{1}$ are the maximum number of bound ligand. equilibrium constant and Hill constant for the first set of binding sites. respectively, and $g_{2} . K_{2}$ and $n_{2}$ are cited parameters for the second set of binding sites. These thermodynamic parameters were estimated by fitting of above equation to experimental data by Signaplot 2000 .

The results were tabulated in Table l. This table shows that the binding constant in the first binding set is higher than that of the second binding set. Maximum number of bound ligand $(g)$ is higher than first binding site. Because in the first step. POM binds to the positive charge on the protein and then unfolding of HSA occurs predominately after saturation of binding sites and then more binding sites become accessible to solvent and ligand.

Hill coefficient $(n)$ shows the cooperativity of ligand binding process. It reveals that binding of POM facilitates the binding of next ligand. Also the Table 1 shows the effect of temperature on the binding parameters. Increase in temperature, make $n_{1}, n_{2}$. increase and decreases $K_{1}, K_{2}, g_{1}$ and $g_{3}$. It seems that complexation decreases as temperature increases. Because ligand binding is mostly exothermic.

\begin{tabular}{|c|c|c|c|c|c|c|c|c|c|c|}
\hline$t /{ }^{\circ} \mathrm{C}$ & $K_{1} \times 10^{-5}$ & $K_{2} \times 10^{-5}$ & $n_{1}$ & $n_{2}$ & $g_{1}$ & $g_{1}$ & $\Delta H_{b}^{o}(1)$ & $\Delta H_{b}^{\prime}(2)$ & $\Delta b_{b}^{\prime}(1)$ & $\Delta S_{b}^{\prime}(2)$ \\
\hline 27 & $2.69( \pm 0.14)$ & $0.27( \pm 0.01)$ & $1.53( \pm 0.09)$ & $4.5( \pm 0.43)$ & $5.5( \pm 0.2)$ & $10.5( \pm 0.5)$ & -40.655 & -12.397 & -31.57 & 43.51 \\
\hline 37 & $1.59( \pm 0.09)$ & $0.23( \pm 0.02)$ & $1.43( \pm 0.16)$ & $5.71( \pm 0.50)$ & $40( \pm 0.2)$ & $7.6( \pm 0.3)$ & & & & \\
\hline
\end{tabular}

In addition. total enthalpy of binding in each set of binding

Table 1. Hill binding parameters for $\mathrm{K}_{0}$ at $\mathrm{pH}=6$. The paranneters were obtained from fitting of equation (10) to experimental data. $K, \Delta H_{b}^{\circ}$ and $\Delta S_{b}^{\circ}$ are in $\mathrm{M}^{-\mathrm{j}}, \mathrm{k}, \mathrm{J} / \mathrm{mol}$, and $\mathrm{T} / \mathrm{mol} \mathrm{K}$, respectively 
site. $\Delta H_{b}^{0}$, can be estimated using $K$ values in two temperature and vant: Hoff equation:

$$
\ln \left(\frac{K_{2}}{K_{1}}\right)=\frac{-\Delta H_{b}^{o}}{R}\left(\frac{1}{T_{2}}-\frac{1}{T_{1}}\right)
$$

Using following equation we can also obtain the entropy change of binding process.

$$
\Delta G_{b}^{o}=\Delta H_{b}^{o}-T \Delta S_{b}^{o}
$$

The results are tabulated in Table 1. $\Delta H_{b}^{\circ}$ (1) for the first set is more negative than that for the second set. The number of positive group for the first set may be higher than second set and so electrostatic interaction and exothermicity become higher. $\Delta S_{b}^{\diamond}$ is negative and positive for the first and second set. respectively, since the number of free molecules decreases. as ligand binding occurs. Therefore the entropy. which depends on the number of these free molecules. will diminish. Sometimes, ligand binding process is accompanied with unfolding. In this case. sone of connections are disrupted and mobility of atoms and residues are increased. Thus the entropy in the unfolded state is higher than that in more compacted form.

In addition, fluorescence spectroscopy was used to monitor changes on the tertiary structure induced by the interaction with ionic POM. These interactions can. in principle, produce changes in the position or orientation of the tryptophan residues. altering their exposure to solvent and leading to an alternation in the quantum yield. Titration of HSA solutions in phosphate buffer at $\mathrm{pH} 6.0$ with $\mathrm{POM}$ were performed by adding aliquots of POM stock solution directly to the cuvette and the fluorescence emission spectra were registered. The study of conformational and functional changes of HSA after interaction with POM by fluorescence showed two phenomena. The first is the reduction of fluorescence inten-

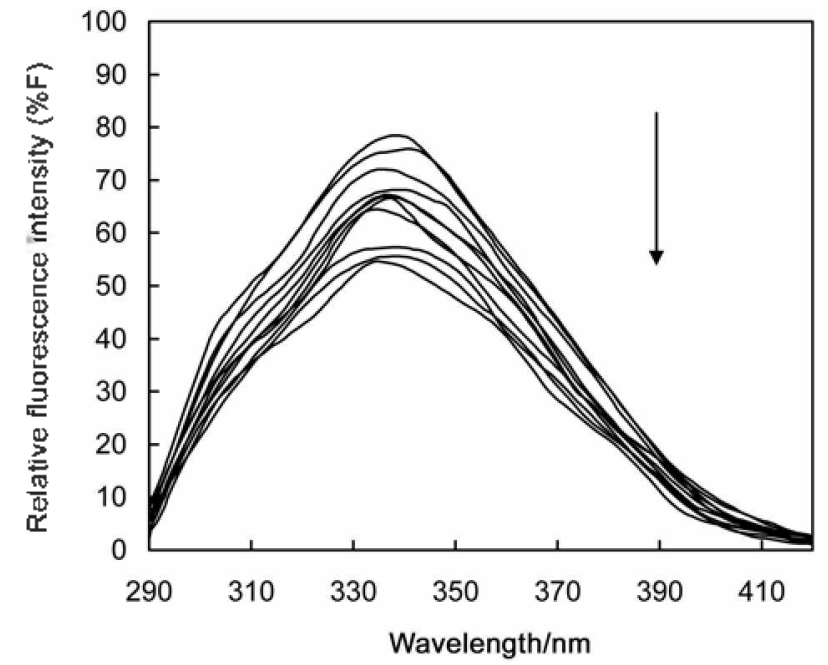

Figure 3. Emission spectra of HSA $(0.03 \mathrm{mg} / \mathrm{mL})$ in $10 \mathrm{mM}$ phosphate buffer at $\mathrm{pH}=6$ and $27^{\circ} \mathrm{C}$. Excitation carried out at 290 nm in different ratio of [POM]/[HSA] same as Figure 4. The arrow in the figure shows that, the increasing the POM concentration is accompanied with decreasing the fluorescence intensity. The lowest spectrum corresponds to the highest concentration of POM. sity and the second is a shift in $\lambda$ at maximum intensity ( $\left.\hat{\lambda}_{\text {max }}\right)$ of emission toward lower wavelength. This implies that confomational changes have occurred.

It is also reported that. the $\operatorname{Trp} 214$ is conserved in manmalian albumins and play an important structural role in the formation of the IIA binding site by limiting the solvent accessibility. In addition, it participates in additional hydrophobic packing interaction between IIA and IIIA interface. This is the reason that HSA takes the heart shape.

Figure 3 shows the variation of fluorescence spectrum in the presence of different concentrations of POM. It is observed that a quenching of fluorescence occurs by POM. Alternation of $\lambda_{\max }$ and fluorescence intensity $(\% \mathrm{~F})$ at $\lambda_{\max }$ were obtained from the Figure 3 and plotted against [POM]/ [HSA] ratio which is depicted in Figure 4.

When $\operatorname{Trp}$ is rigid and shielded against interaction with other molecules, then the energy transfer and following quenching is low. Increasing the interaction of Trp with other molecules such as. solvent and ligand molecules. make increases the energy transfer from Trp to other molecules and the intensity increases (increases quenching).

Figure 4 also shows the comparison of calorimetery and fluorescence results. It is significant to note to the similar trend in the calorimetery and fluorescence data. Calorimetery data shows that ligand binds to HSA electrostatically in the first. The exothermic interactions (mostly electrostatic) correspond to decreasing part of heat curve. Thus the injection of more ligands releases the heat. This released heat due to binding. causes dissociation of some of connections (except covalence bond) and results in unfolding of protein. Therefore. this later process is endothernic. We see two minima in calorimetry and fluorescence curves which are related to presence of two structural domains for binding. Because. the $\mathrm{X}$-ray crystallographic data and the three-dimensional struc-

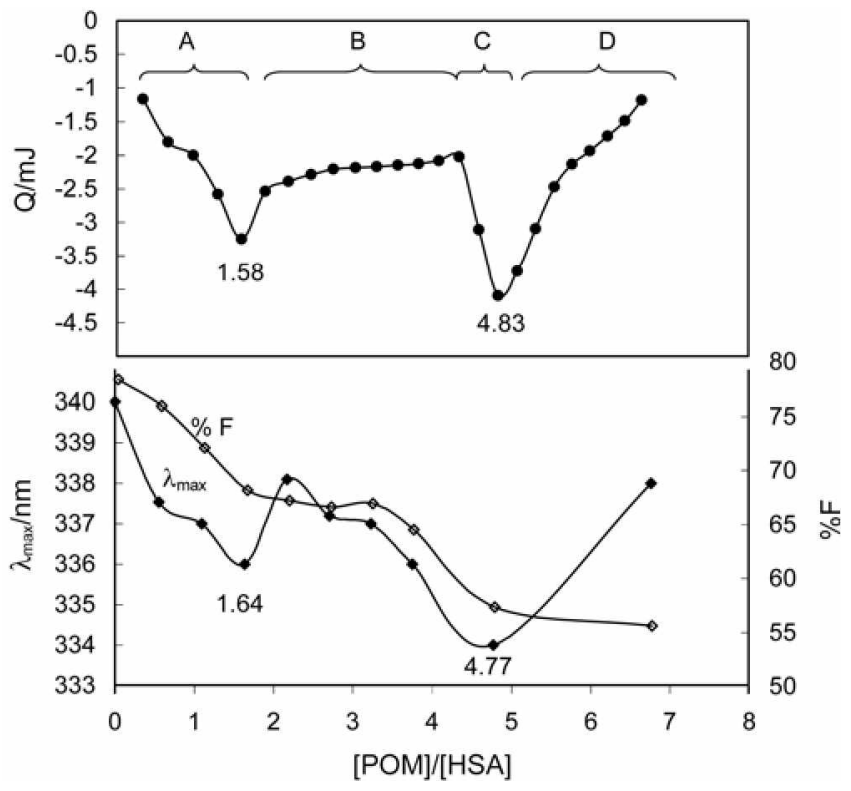

Figure 4. Heat of mteraction of POM with HSA (up) and fluorescence intensity as well as $\lambda_{\text {tilax }}$ (down) in difterent ratio of $[\mathrm{POM}] /[\mathrm{HSA}]$ and $10 \mathrm{mM}$ phosphate butter at $\mathrm{pH}=6$ and $27{ }^{\circ} \mathrm{C}$. 
ture of HSA showed two distinct segments. ${ }^{7,31}$ One extra compacted segment as the head of HSA molecule, which is the result of intermolecular interactions of IA, IB and IIA subdomains. Whereas another segment. tail of the molecule. is more extended than the head part and contains IIB, IIIA and IIIB subdonains. The stability of the tail is less than the head part and has a loose conformation when compared to the head region. ${ }^{7,31}$

Thus, two minima in the Figure 4 are probably related to bindings to the cited domains. First ( $\mathrm{A}$ and $\mathrm{B}$ steps) and second ( $C$ and $D$ steps) minima correspond to interaction of ligand to more and less accessible domain, respectively. The $A$ and $C$ sections are related to an increase in exothermicity. while $\mathrm{B}$ and $\mathrm{D}$ correspond to a decrease in exothermicity (increase in endothermicity due to unfolding). Because unfolding process is the endothernic process. On the other hand, rate of quenching (curvature of $\% \mathrm{~F}$ curve ) in $\mathrm{A}$ and $\mathrm{C}$ is higher than that in $B$ and $D$. $\hat{\lambda}_{\max }$ goes to lower wavelength in $A$ and $C$ and to higher wavelength than that in $B$ and $D$. The cause of these observation is that the interaction of POM with HSA makes increasing the energy transfer (quenching) due to proximity of Trp or other fluorofores to ligand and solvent molecules following increasing its flexibility and accessibility. When the electrostatic interaction goes to minimum or saturates the opposite charge by POM. then repulsion between the negative charge of ligand and $\pi$ electrons of aromatic ring lead the fluorofore to a region of less polarity ( $\hat{\lambda}_{\text {max }}$ goes to higher wavelength at $B$ and $D$ ).

Thus, $A$ and $C$ steps correspond to a decrease in endothermicity, $\lambda_{\max }$ and $\% \mathrm{~F}$, whereas $\mathrm{C}$ and $\mathrm{D}$ steps are related to an increase in endothermicity, $\hat{\lambda}_{\text {max }}$ and slow decrease in $\% \mathrm{~F}$.

Figure 5 shows the variation of $C_{p}^{\text {excess }}$ of HSA versus temperatures when incubated with POM. The reversibility of the thermal denaturation of the samples up to $80{ }^{\circ} \mathrm{C}$ was assayed by rescanuing after cooling the saniple that was previously scanned thermally. Also, Figure 6 contains the deconvolution results of thermal profile. Deconvolution of excess heat capacity into sequential two-state transitions was carried out in upward direction by utilization of Scal-2

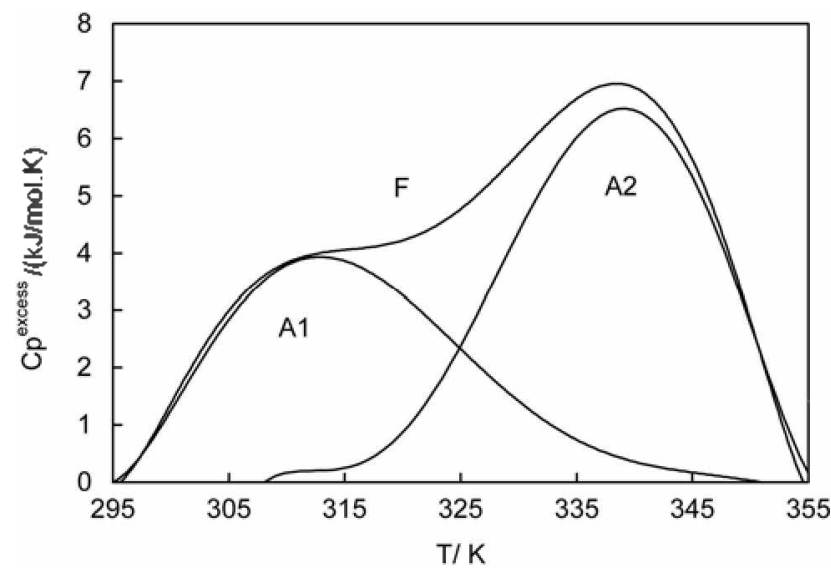

Figure 5. Thernogram of human serum albumm (HSA) in the presence of $0.045 \mathrm{mM}$ of $\mathrm{POM}$ in $10 \mathrm{mM}$ phosphate buffer. Subpeaks were obtained by deconvolution of $C_{p}$ ineso profile.

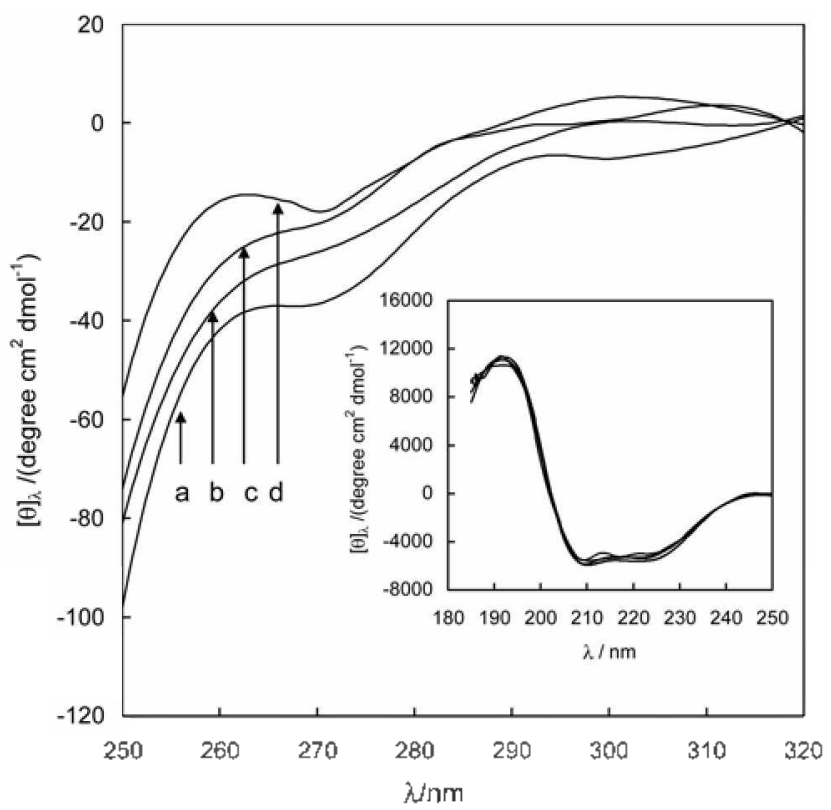

Figure 6. Near and far (inset of tigure) UV circular dichroism spectra of the HSA protein. CD spectra were recorded for the HSA protein in the absence (a) and presence of (b) 4 (c) $9 \mathrm{~d}$ (14) molar ratio of $[\mathrm{POM}] /[\mathrm{HSA}]$. The HSA concentration was $0.3 \mathrm{mg} / \mathrm{mL}$ and $3.0 \mathrm{mg} / \mathrm{mL}$ for far and near UV-CD, respectively.

software. The resulting deconvolution parameters were optimized by fitting program of the related software. The calculated fitting error was less than 0.015 that represent energetic domains with special $T_{n i}$ and enthalpy of unfolding $\left(\Delta H_{m i}\right)$. The thermal denaturation profile of HSA in the absence of POM was reversible up to $75^{\circ} \mathrm{C}$ (data not shown). Therefore the denatured line was not accessible and it is impossible to obtain the deconvolution profile for HSA in the absence of POM. ${ }^{12}$

DSC data shows that there are two energetic domains in themal profile. One of them. has lower $T_{n i}$. and $\Delta H(313 \mathrm{~K}$ and $136 \mathrm{~kJ} / \mathrm{mol}$ ) that may be related to unfolding of weak binding or tail of HSA and the other with higher $T_{m}$ and $\Delta H$ ( $338 \mathrm{~K}$ and $141 \mathrm{~kJ} / \mathrm{mol}$ ) is related to more compact domain and stronger parts of molecule (head of HSA).

Figure 6 shows the effect of different concentration of $\mathrm{K}_{S}$ on the secondary and tertiary structure of HSA. The values of different parts of CD were tabulated in Table 2. POM reduces the secondary and tertiary structure. The results show that the tertiary structure has changed relatively more than the secondary structure. It shows that $\alpha$-helix decreases, $\beta$-structure increases and random coil variation are not regular. Last colunu of this table also shows fluorescence

Table 2. The effect of POM on the secondary structure and fluorescence intensity at $\mathrm{pH}=6$ and $27^{\circ} \mathrm{C}$

\begin{tabular}{ccccc}
\hline$\left[\mathrm{K}_{6}\right] /[\mathrm{HSA}]$ & Alpha Helix \% & Beta Structure \% & Random\% & $\% \mathrm{~F}$ \\
\hline 0 & 30.4 & 41.0 & 28.6 & 81.1 \\
4 & 29.9 & 41.6 & 28.5 & 37.4 \\
9 & 29.5 & 43.2 & 27.2 & 27.8 \\
14 & 29.3 & 42.2 & 28.4 & 23.2 \\
\hline
\end{tabular}




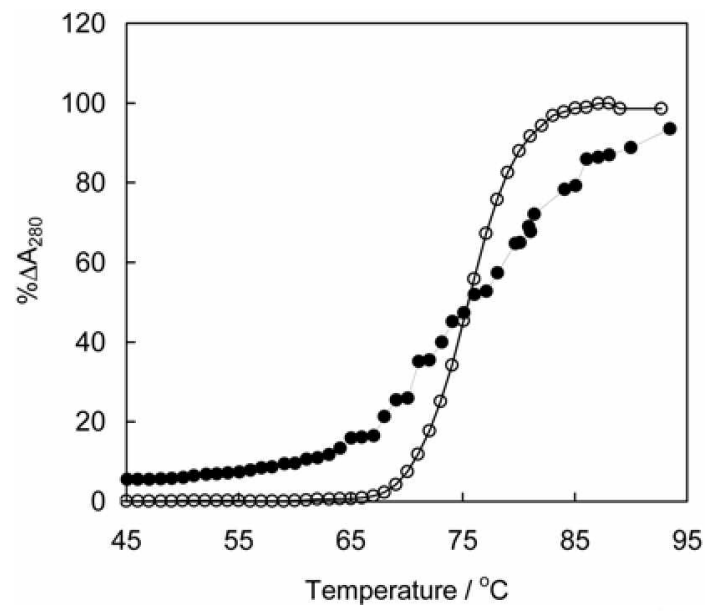

Figure 7. Temperature scanning of $280 \mathrm{~nm}$ absorbance for HSA $(0.50 \mathrm{mg} / \mathrm{mL})$ in the absence $(1)$ and the presence $(-)$ of $3 \times 10^{-5}$ $\mathrm{MK}_{\mathrm{D}}$.

intensity $(\% \mathrm{~F})$ in the same ratio for comparison of structural changes in two methods.

On the other hand, midpoint of thermal transition $\left(T_{\mathrm{n}}\right)$. as a parameter for comparison of the thermal stability, obtained from Figure 7. It shows percent of variations at $280 \mathrm{~nm}(\%$ $\left.\Delta A_{\text {s } 81)}\right)$ for deternination of $T_{\mathrm{m}}$. It can be obtained from derivation of the curve of Figure 7. As we see. POM decreases the $T_{\mathrm{m}}$ of protein from 78 to $73^{\circ} \mathrm{C}$. Thus POM destabilizes the HSA.

\section{Conclusion}

Ligand binding process often associates with denaturation of macromolecues (folding or unfolding). Some of them are exothermic (such as electrostatic interaction) and others are endothermic (such as unfolding). Thus, the prinary interactions are usually electrostatic. Heat of exothermic process supports the unfolding process. Therefore the required heat for unfolding is often obtained from exothermic interactions. Downward trend of heat curve is related to exothemic (mostly electrostatic) and upward trend of curve is related to endothernic (mostly unfolding) process. Variations of calorimetry and fluorescence data show a common fact. Their curves have two minima. First minimum corresponds to interaction with more exposed positive amino acids and less stable domain (lower $T_{\mathrm{m}}$ and $C_{\mathrm{p}}$ in DSC and UV experiments) and the second minimum is related to less exposed positive amino acid and more stable domain. Entropy change in the first set is negative whereas in the second site is positive. Interaction with the first set in here is more favorable because it has higher binding constant $(K)$ and it is prior to the second. The first set is thermodynamically less stable. Thus we can ascribe it to the tail of HSA and more stable domain relates to head of HSA. Also POM ligand destabilizes the protein structure.

Acknowledgment. The financial supports of the Research
Council of Damghan University of Basic Science with grant number 5965 and Research Council of University of Tehran are acknowledged.

\section{References}

1. Shakai. N.: Garlick. R. L.: Bun11. H. F. J. Biol Chem. 1984. 259. 3812 .

2. Carter. D. C.: Ho. J. X. Adt: Protein Chem 1994. 45.153.

3. Figg. J.: Rossing. T. H; Fencle, V. J. Lab. Hed. 1991. 117,453.

4. Kragh-Hansen, U. Pharmacol Rev 1981. 33, 17.

5. Brown. J. R:- Shockely: P. In Lipid-Protein Mneraction Jost. P. C.; Griffith. O. H.. Eds.: Wiley: New York. 1982: vol. 1. pp 26-28.

6. Carter. D. C.: Chang. B.: Ho. J. X.: Keeling. K.: Krishnasami. Z Eur. J. Biochent. 1994. 226.1049.

7. He. X. M.: Carter, D. C. Natwe 1992. 358. 209.

8. Curry, S.: Mandelkow, H.: Brick. P.: Franks. N. Kat. Struct. Biol. 1998. 5,827 .

9. Peters. T. Adwances in Protein Chentistry: Academic Press: New York. 1985: vol. 37. pp 161-245.

10. Narazaki. R.: Mauyama. T.: Otagiri. M. Biochint. Biophns .Acto $1997.1338,275$.

11. Galemo. E. L.: Tabak. M. Spectrochimica Acta Part \& 2000. 56. 2255 .

12. Mohammadi-Nejad. A.: Moosavi-Movahedi. A. A.: Satarian. S.: Naderi-Manesh. M. H.: Ranipar. B.: Falzami. B.: Mostatavi. H.: Larijani. M. B.: Hakimelahi. G. H. Thentichintica Acta 2002. 389. 141 .

13. Clerea. E. D. Bioned \& Phamacother 1996. 50,207.

14. Rhule, J. T: Hill. C. L.: Judd, D. A.; Schinazi. R. F. Chem. Rev 1998. 98.327

15. Katsoulis. D. E. Chem. Rev: 1998. 98.359.

16. Pope. M. T. Heteropoly and Isopoly Oxometalates: SpringerVerlag: Berlin. 1983.

17. Yamamoto. N.: Schols. D.: Clerce, E. D.: Debyser. Z.: Pauwels. R.: Balzarini, J : Nakashima, H.: Baba. M.; Hosova, M.: Snoeck R.: Neyts. J.: Andrei. G.: Murrer. B. A.: Theobald. B.: Bossard. G.: Henson. G: Abrams. M.: Picker. D. Hol Phamacol 1992. +2 1109.

18. Bordbar. A. K.: Sohrabi. N.: Tangestaninejad. S. Physics and Chemisty of Liquids 2004. 12.127.

19. Moosavi-Movahedi, A. A. Thermodnamics and Binding Properties of Sinfactant-protem interactions in the Encyclopedia of Surface and Colloid Science: Marcel Delker. Inc.: New York. 2002: pp 5344-5354.

20. Saboury, A. A.; Bordbar. A. K.: Moosavi-Movahedi, A. A. Bull. Chem. Soc. Japan 1996, 69, 3031.

21. Housaindokht, M. R.; Bahrololoom. M:- Tarighatpoor. S.; MoosaviMovahedi. A A. Acta Biochinica Polnica 20102. +9.703 .

22. Pedersen. P. V.J. Phamacentical Sci. 1978. 67.908.

23. Ajlco. D.: Moosavi-Movahedi. A. A.: Hakimelahi. G. H.: Saboury: A. A.: Gharibi, H. Colloids and Surfaces B: Biointerfaces 2002. 26. 185

24. Bathaie, S. Z.; Moosavi-Movahedi, A. A.: Saboury. A. A. Nucleic Acids Research 1999. 25. 1001

25. Saboury. A. A. J. Chem. Thennodm. 2003. 35. 1975.

26. Ochoa. D.: Aspuru. E.: Zaton. A. M. J. Biochentical and Biophnsical Hethods 1993, 27.87.

27. Teze, A.: Herve. G. Ihorg. Chem 1977.39.2151

28. Knoth, W. H.; Domail, P. J.: Farlee, R. D. Organometallics 1985. +. 62 .

29. Fitlke. R. G: Droge. M. W.: Domail. P. J. homg. Chent 1987. 26. 3886.

30. Hill, A.V. J. Phusiol $1910,40,4$

31. Carter. D. C. He. X. M.: Munson. S. H.: Twigg, P. D. Gernert. K M.; Broom, M. B.: Miller. T. Y. Science 1989. 2tt, 1117. 